\title{
Co-axial Feed Circularly Polarized Rectangular Microstrip Patch Antenna with 'O' Slot for UWB Application
}

\author{
Mr. Gajanan H. Wankhade ${ }^{1}$, Prof. Md. Aslam², Prof. Hema Singh ${ }^{3}$ \\ M. Tech. Scholar, Electronics \& Communication, TIT Excellence, Bhopal, R.G.P.V. Bhopal, India ${ }^{1}$ \\ Assistant Professor, Electronics \& Communication, TIT Excellence, Bhopal, R.G.P.V. Bhopal, India ${ }^{2}$ \\ HOD, Electronics \& Communication, TIT Excellence, Bhopal, R.G.P.V. Bhopal, India ${ }^{3}$
}

\begin{abstract}
In this project a design of co-axial feed circularly polarized rectangular microstrip patch antenna with ' $O$ ' slot for UWB application. Here microstrip patch antenna is designed to improve the efficiency as well as bandwidth. The microstrip patch antenna is very popular for its low profile, low cost, light weight, easy to feed, and their attractive application. The return loss is below $-25 \mathrm{~dB}$ from $2 \mathrm{GHz}$ to $4 \mathrm{GHz}$. A maximum gain achieved at $3.5 \mathrm{GHz}$ frequency. The VSWR is less than 2. The substrate material of RT-duriod-5880 with relative permittivity 2.2 and loss tangent of 0.009 is used in this proposed antenna. The input impedance and VSWR have been measured with the help of Network analyser. The total simulation done on Ansoft High Frequency Structure Simulator (HFSS) software.
\end{abstract}

Keywords: Bandwidth (BW), High Frequency Structure Simulator (HFSS), Voltage Standing Wave Ratio (VSWR), Ultra Wide Band (UWB).

\section{INTRODUCTION}

Recently, the demand of antenna is rapidly increases due to varieties of wireless communication. Among all types of antennas, they can be classified into two categories which are linearly-polarized and circularly-polarized antenna. For satellite communication and high sensitivity systems like as GPS, satellite phone and the space-to-earth communication, The circularly-polarized antenna must be used in order to maintain good capability of signal strength.

A microstrip patch antenna, is just a rectangular corner truncated conductive plate that is placed above a ground plane. The Ultra wide band (UWB) communication system is used for transmitting coded signal at low power and high bit data rate. The microstrip patch antennas are attractive for their features such as low manufacturing cost, light weight, conformal, ease to feed. A microstrip antenna consisting of conducting patch on a plane surface separated by a dielectric substrate.

For good antenna performance a thick dielectric substrate having low dielectric constant is desirable. Considering the nature of the substrate material to be chosen, for higher bandwidth, the dielectric constant must be low. For smaller size, the dielectric constant must be high. A microstrip patch antenna is characterized by its length, width, input impedance, gain, radiation patterns.

The length of antenna is nearly half wavelength in the dielectric. The loading of the slots in the radiating patch can cause meandering of the excited patch surface current paths and result in lowering of the antennas fundamental resonant frequency, which corresponds to the reduced antenna size for such an antenna compared to conventional microstrip antenna at same operating frequency.
There are multiple and well known methods to increase the BW, including and matching techniques, and use of multiple resonators. A wide band with high gain antenna fed to co-axial probe is presented. The height of the dielectric constant is kept constant $1.5 \mathrm{~mm}$. In this paper, we investigate the parameter of proposed microstrip patch antenna using ' $O$ ' slot for smaller dimension, better efficiency and high bandwidth.

\section{ANTENNA DESIGN AND SPECIFICATION}

In this paper, several parameters have been investigated using Ansoft HFSS software. The geometry of the proposed a co-axial feed o-slotted circularly polarized corner truncated patch antenna is shown. It is fabricated on RT-Duriod substrate with a dielectric constant of $\varepsilon=2.2$ and substrate thickness is $t=0.32 \mathrm{~cm}$. The antenna is fed by $50 \mathrm{ohm}$ co-axial probe, through a quarter wavelength transformer for impedance matching. The proposed antenna has a simple configuration consisting of ' $\mathrm{O}$ ' slot and parasitic patch. The radius of the slot determines the lower resonant frequency, with an increasing radius; the lower resonant frequency is shifted downward.

The antenna has the following parameters $R_{1}=1.5 \mathrm{~cm}$; $R_{2}=2 \mathrm{~cm} ; \mathrm{L}=4 \mathrm{~cm}$. In order to obtain a stable symmetrical radiation pattern, the parasitic patch is embedded into the center of the slot. To simply the design, the width of the feed line is chosen to be $3 \mathrm{~mm}$. In here, the radius is the distance between the slot center and edge of the feed line. Based on the simulated results, the radius of the feed structure can be adjusted for good impedance matching.

The proposed antenna has better bandwidth, better efficiency and much smaller size. Some techniques are 
used to compact antenna and some techniques are used to enhance the efficiency of antenna based on recent designs slotted microstrip antennas have been proposed. Rectangular patch can be modeled as microstrip transmission line, because these antennas have a physical shape derived from microstrip transmission lines. Therefore, transmission line model is one of the most intuitively appealing model for analysis the rectangular microstrip patch antenna.

The circular polarized antenna have an advantage in reducing the loss caused due to polarization misalignment between signals and receiving antenna. The advantages of co-axial feeding technique are the feed can be placed at any location at patch in order to achive better impedance matching and to avoid unwanted radiation from the feed. The design of proposed antenna is shown in figure-1

\begin{tabular}{|c|c|}
\hline Antenna Parameters & Dimension \\
\hline Length of Rectangular patch & $4 \mathrm{~cm}$ \\
\hline Width of Rectangular patch & $3 \mathrm{~cm}$ \\
\hline Thickness of the substrate & $0.32 \mathrm{~cm}$ \\
\hline Relative Permittivity of the Substrate & 2.2 \\
\hline Radius of inner circle $\left(R_{1}\right)$ & $1.5 \mathrm{~cm}$ \\
\hline Radius of outer circle $\left(R_{2}\right)$ & $2 \mathrm{~cm}$ \\
\hline
\end{tabular}

Table-1:Antenna Parameters Dimension for proposed antenna

\section{DESIGN OF PROPOSED ANTENNA}

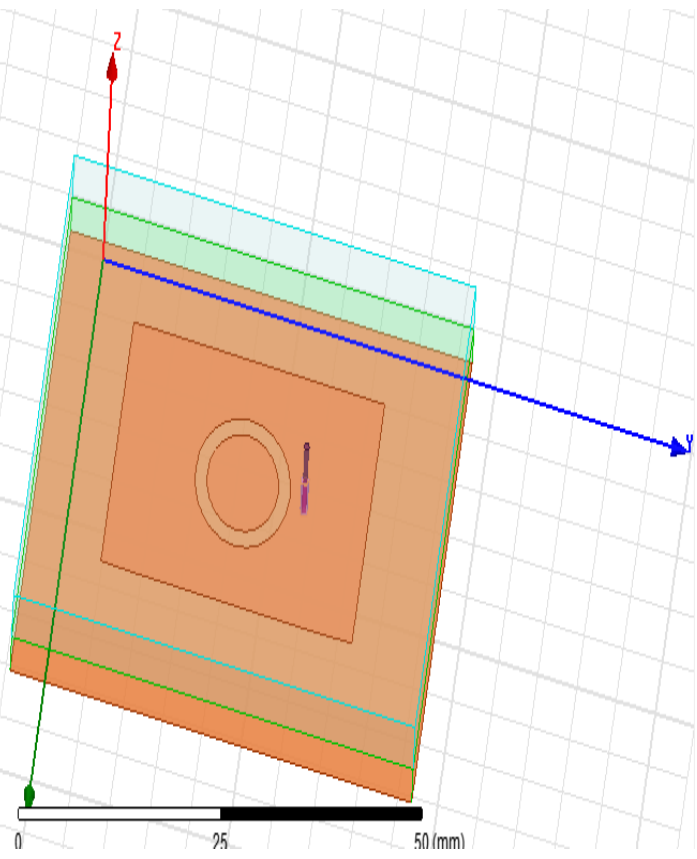

Figure 1: Co-axial feed ' $\mathrm{O}$ ' slot circularly polarized rectangular microstrip patch antenna.
IV.

FLOW CHART FOR ANTENNA DESIGN

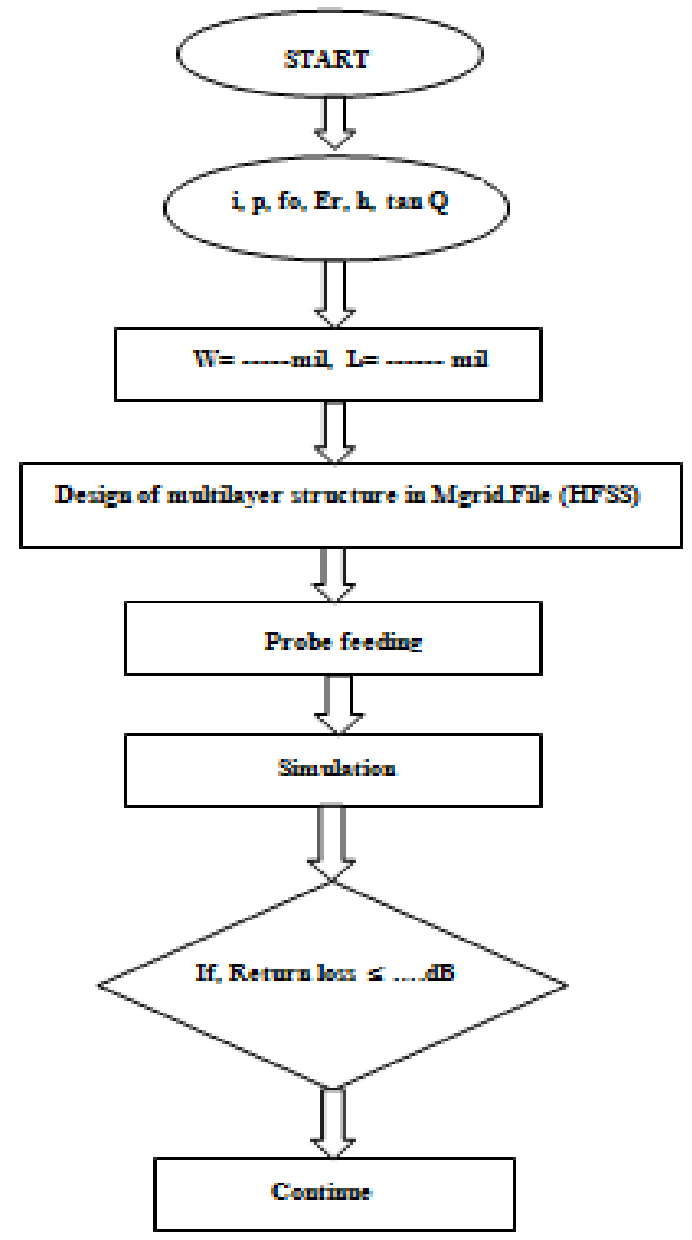

V. MATHEMATICAL FORMULATION

$$
L_{e f f}=\frac{c}{2 f_{o \sqrt{\varepsilon_{r e f f}}}}
$$

$L_{e f f}=$ Effective length of the patch

$f_{o}=$ Operating frequency of the antenna

$\mathrm{c}=$ Speed of light

$\varepsilon_{\text {reff }}=$ Effective dielectric constant

Because of the fringing effects, electrically the patch of the microstrip antenna looks greater than its physical dimensions.

The amount of fringing is a function of the dimensions of the patch and the height of the substrate.

$$
W=\frac{c}{2 f_{o} \sqrt{\frac{\left(\varepsilon_{r}+1\right)}{2}}}
$$

$W=$ Width of the patch

$\varepsilon_{r}=$ Dielectric constant of the substrate

$$
\begin{gathered}
\varepsilon_{\text {reff }}=\frac{\varepsilon_{r}+1}{2}+\frac{\varepsilon_{r}-1}{2}\left[1+12 \frac{h}{W}\right]^{-\frac{1}{2}} \\
\mathrm{~h}=\text { height of the patch }
\end{gathered}
$$

For low frequencies the effective dielectric constant is essentially constant.

The fundamental resonant frequency of an antenna is 
$f_{r}=\frac{c}{\pi \sqrt{R_{1}+R_{2}}} \sqrt{\frac{1+\varepsilon_{r}}{2 \varepsilon_{r}}}$

$f_{r}=$ Resonant frequency of an antenna

$R_{1}=$ Radius of inner circle

$R_{2}=$ Radius of outer circle

\section{RESULT AND DISCUSSION}

The characteristics of the proposed antenna were calculated by Ansoft High Frequency Structure Simulator (HFSS) software. Measured return loss and input impedance on a Smith chart for the proposed antenna. By designing the edges of the radiating patch in the form of circle shape slot, an additional resonance is generated and the impedance BW of the micro strip antenna is improved. The quality between the width of patch and width of the surface plane is also important parameter to getting the suitable required radiation characteristics.

\section{CONCLUSION}

This paper proposed a co-axial feed circularly polarized microstrip patch antenna with ' $O$ ' slot for wireless communication systems. Various parameters of antenna design are optimized. In this paper, we measure the result of return loss, VSWR, Radiation pattern, efficiency and bandwidth of the proposed antenna design and which ensures that this antenna gives very good performance in wireless communication applications. The proposed model of the antenna can be used for a variety of UWB applications including high speed data transfers, wireless connectivity between UWB-enabled devices and a variety of medical applications.

\section{REFERENCES}

[1] [1] Constantine A. Balanis, "Antenna Theory Analysis and Design", John Wiley \& Sons, INC., Publications New York.

[2] [2] Wenkuan Chen, Yuanxin Li, Xin Hu, Hongyan Jiang, Yunliang Long “A New Design of Tri Frequency Micro Strip Patch Antenna with Arc Slots" China, 2012 IEEE.

[3] [3] Evangelos S. Angelopoulos, Argiris Z. Anastopoulos, Dimitra I. Kaklamani, Antonis A. Alexandridis, Fortis Lazarakis and Kostas Dangakis "Circular and Elliptical CPW-Fed Slot and MicrostripFed Antennas for Ultrawideband Applications" IEEE Antenna \& wireless Prop. Letters, Vol. 5, 2006

[4] [4] C. F. Tseng, S. C. Lu, Y. C. Hsu "Design of Microstrip Antenna with Modified Annular-ring for GPS Application" PIERS Proceedings, Suzhou, China, Sept 2011.

[5] [5]Dhaval Dhupar, Prateek Chandra, Rahul Anand, Rajesh K. Vishwakarma “ Microstrip Antenna With Hexagonal Slots for UWB Application” 2013 Intrernational Conferance on Communication Systems and Network Technology, Guna.

[6] [6] R. Jothi Chitra, M. Yoganathan and V. Nagarajan "Co-axial Fed Double L-Slot Microstrip Patch Antenna Array for WiMAX and WLAN Application" International Conference on Communication and Signal Processing, April 3-5, 2013, India

[7] [7] G. P Gao, M. Li, S. F. Niu, X. J. Li, B.n. Li and J. S. Zhang "Study of a Noval Wideband Circular Slot Antenna having Frequency Band-Notch Function" Progress in Electromagnetic Research, PIER 96, 141-154, 2009, China.

[8] [8] Md. Imran Hasan, M. A. Motin, Md. Samiul Habib "Circular ring slotting technique of making compact microstrip rectangular patch antenna for four band application" IEEE 2013

9] [9] Ram Singh Kushwaha, D. K. Srivastava, J. P. Saini “ A Design of H-shape slot loaded wideband Microstrip Patch Antenna" IJECSE, India

[10] [10] Md. Maruf Ahamed, Kishore Bhowmik, Md. Shahidulla, Md. Shihabul Islam, Md. Abdur Rahman "Rectangular Microstrip Patch Antenna at $2 \mathrm{GHz}$ on Different Dielectric Constant for Pervasiv Wireless Communication" IJECE, 2012, Bangladesh.

\section{BIOGRAPHY}

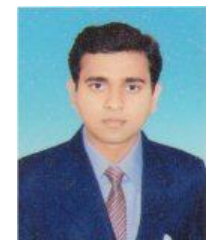

Mr. Gajanan H. Wankhade M. Tech. (E \& Comm.) Scholar in Technocrats Institute of Technology (Excellence), Bhopal under R.G.P.V. Bhopal. B.E. in Electronics \& Communication from M.I.E.T. Gondia under R.T.M. Nagpur University. 